\title{
How to measure dietary intake and food habits in adolescence: the European perspective
}

\author{
LA Moreno $^{1 *}, \mathrm{M} \mathrm{Kersting}^{2}$, S de Henauw ${ }^{3,4}, \mathrm{M}$ González-Gross ${ }^{5}$, W Sichert-Hellert ${ }^{2}$, C Matthys ${ }^{3}$, \\ MI Mesana ${ }^{1}$ and $\mathrm{N}$ Ross ${ }^{5}$
}

\begin{abstract}
${ }^{1}$ Escuela Universitaria de Ciencias de la Salud, Universidad de Zaragoza, Zaragoza, Spain; ${ }^{2}$ Research Institute of Child Nutrition (FKE), University of Bonn, Germany; ${ }^{3}$ Department of Public Health, Ghent University, Ghent, Belgium;

${ }^{4}$ Department of Health Sciences, Vesalius - Hogeschool Gent, Ghent, Belgium; and ${ }^{5}$ Facultad de Ciencias de la Actividad Física y del Deporte, Universidad Politécnica de Madrid, Madrid, Spain
\end{abstract}

\begin{abstract}
AIM: This paper deals with some methodological aspects of data collection in the context of measuring dietary intake in individuals in their adolescence life stage.

METHOD: Experiences from three partners of the HELENA project in dietary intake measurement in children and adolescents are presented in this paper with emphasis on characteristics of under-reporting, long-term diet measurement and food patterns (Dortmund DONALD group), influences of survey duration on under-reporting (Ghent group) and meal habits (Spanish AVENA group).

RESULTS: Under-reporters in the DONALD Study, particularly female adolescents, had a significantly higher body mass index (BMI) than non-under-reporters; BMI could not be explained by different long-term dietary patterns during childhood and adolescence clustered according to fat consumption; consumers of fast food had higher BMI values than nonconsumers. In the Ghent experience, the decline in population mean energy intake as calculated over selected clusters of days is $184 \mathrm{kcal}(6.5 \%)$ in boys and $116(5.6 \%)$ in girls; the cluster of 1 recording day and the cluster of 3 recording days were not significantly different but they were both significantly different from the 7-day cluster; no significant interaction was observed between the effect of time and BMI. In the AVENA Study, the percentage of adolescents skipping breakfast was higher in females (8.6\%) than in males (3.5\%, $P<0.001)$; higher BMI values were observed in those skipping breakfast than in those notskipping breakfast, but differences were statistically significant in males at $15 \mathrm{y}$ and in females at 14 and $17 \mathrm{y}$; adolescents avoiding some food groups for breakfast had higher BMI values (carbohydrates, fruits and pastries in males and milk, fruits and pastries in females).

CONCLUSION: Dietary and nutrient intake data in the HELENA project will be obtained by means of repeated 24-h dietary recalls. Data from HELENA might be a basis for developing complex approaches like Healthy Eating Indices.
\end{abstract}

International Journal of Obesity (2005) 29, S66-S77. doi:10.1038/sj.ijo.0803063

Keywords: adolescents; dietary intake; dietary patterns; under-reporting

\section{Introduction}

Evidence that the nutrition-related risk factors for chronic diseases start in early childhood and adolescence is growing more and more. This has led to increasing interest in studying the adolescent population, which has been much less studied in former years than other population groups. Adolescence is a crucial period in life and implies multiple physiological and psychological changes that affect nutritional needs and habits. Adolescents have particular food choices and meal habits compared to younger children and adults. They differ in irregular eating patterns, frequent

*Correspondence: Professor LA Moreno, E.U. Ciencias de la Salud, Universidad de Zaragoza, Domingo Miral s/n, Zaragoza 50009, Spain. E-mail: Imoreno@unizar.es snacking and frequent skipping of meals, particularly breakfast. These facts render the collection of accurate dietary intake data even more difficult than in other age groups.

The HELENA (Healthy Lifestyle in Europe by Nutrition in Adolescents) Study, supported by the E.U. 6th Framework Programme, includes cross-sectional, crossover and pilot community intervention multicentre studies. One of the main objectives of the project is to obtain reliable and comparable data of a representative sample of European adolescents, concerning dietary intake and food habits. Therefore, there is a need to establish an adequate datarecording methodology.

The prevalence of childhood overweight and obesity has increased in the majority of the countries in the last decades. ${ }^{1-3}$ Obesity is not a single disease, but a complex 
multifactorial condition involving environmental and genetic factors. Among the environmental factors, diet appears to be an important contributor to the development of obesity. The ability for an accurate measurement of dietary patterns and food and nutrient intake in children and adolescents is an essential instrument in the battle against the currently observed disruption of body weight regulation in large parts of the population.

Very recently, a systematic review of surveys of dietary intake and status in children and adolescents conducted in Europe has been carried out by an ILSI Europe Task Force. ${ }^{4}$ Surveys that satisfied a defined set of criteria (published, based on individual intakes, post-1987, adequate information provided to enable its quality to be assessed, small age bands, data for sexes separated above $12 \mathrm{y}$, sample size over 25 and subjects representative of the population) were selected for further analysis. A total of 79 surveys from 23 countries were included and, from them, data on energy, protein, fats, carbohydrates, alcohol, vitamins, minerals and trace elements were collected and tabulated. Data on energy, protein, total fat and carbohydrate were given in a large number of surveys, but information was very limited for some micronutrients. No surveys gave information on fluid, intake and insufficient data were given on food patterns. A variety of collection methods were used, there was no consistency in the ages of children surveyed or the age cutoff points, but most surveys gave data for males and females separately at all ages. Just under half of the surveys were nationally representative and most of the remainder were regional. Males had higher energy intakes (EIs) than females; EI increased with age but levelled off in adolescent girls. Intakes of other nutrients were generally related to EIs. Some north-south geographical trends were noted in fat and carbohydrate intakes, but these were not apparent for other nutrients. Some other trends between countries were noted, but there were also wide variations within countries. The main conclusion was the need for harmonisation and standardisation of the methods of nutrition surveys in Europe.

Designing an instrument to evaluate an adolescent's eating habits requires addressing not only the typical requirements for a diet-assessment tool but also the unique concerns of the adolescent population. A limited number of dietary assessment instruments that are specifically designed for adolescents have been found to be reproducible and validated. There is a demand for short, easily administered, inexpensive, accurate instruments that can be used in a broad range of adolescent subpopulations. ${ }^{5}$

This paper deals with some methodological aspects of data collection in the context of measuring dietary intake in individuals in their adolescence life stage. In general, adolescents are, at the group level, expected to be more prone to reporting bias as part of their general tendency towards a more immature behaviour, and some reluctance in participating in initiatives taken by adults. For adolescents that are confronted with body weight problems, the social pressure concerning eating (both with respect to the type of food they are eating and the amounts of food) are expected to add to the already mentioned problems.

Experiences from three partners of the HELENA project in dietary intake measurement in children and adolescents are presented in this paper, with an emphasis on characteristics of under-reporting, long-term diet measurement and food patterns (Dortmund DONALD group), influences of survey duration on under-reporting (Ghent group) and meal habits (Spanish AVENA group).

\section{The Dortmund Nutritional and Anthropometric Longitudinally Designed (DONALD) Study}

The DONALD Study, an ongoing mixed cohort study that started in 1985, covers the age range of $0.25-18 \mathrm{y}$ in healthy infants, children and adolescents. In this study, repeated 3D weighed food records were collected together with body weight and height measurements in a longitudinal design with an identical methodology over the full age range since the start of the study. ${ }^{6}$ Among others, these data give the unique opportunity to examine age effects on the nutritional and preventive quality of the diet and on the validity of dietary intake measurements as well as associations of dietary intake and body weight (obesity).

\section{Characteristics of under-reporting}

In the DONALD Study, age effects were found for the responsibility of the family members for the diet records. While some children from the age of $7 \mathrm{y}$ assisted their parents in recording, $80 \%$ of the $10-12$ y olds already helped. In the adolescents, totally self-reliant records were kept by $20 \%(30 \%)$ of the males (females) at the age of $13-14 \mathrm{y}$ and by $70 \%(90 \%)$ above 15 y of age. ${ }^{7}$

In epidemiological studies, the problem of under-reporting can be evaluated by a statistical method, proposed by Goldberg et $a l,{ }^{8}$ relating measured EI to individual (predicted) basal metabolic rate (BMR) in a ratio EI:BMR (see also Ghent group). However, 'Cutoff 2' values for plausible EI:BMR ratios calculated for adults are not per se adequate for younger age groups. Therefore, Cutoff 2 values were recalculated for children and adolescents based on specific intraindividual variation of EI. ${ }^{9}$

Under-reporting (\% of not plausible low EI) was then identified as age and sex specific in the DONALD Study and (except the 14-18-y-old males) lower for the recalculated than for the original Cutoff 2 values particularly for females, with $1 \%$ lowest in the $1-5 y$ olds, $2-3 \%$ in the $6-13 y$ olds, but manifestly higher in the adolescent groups and obviously dependent on sex, with $12 \%$ for males and $20 \%$ for females. Using the Cutoff 2 values proposed for adults would have increased numbers of not plausible records in female adolescents up to $30 \%$. 
Under-reporters in the DONALD Study, particularly female adolescents, had a significantly higher BMI than non-underreporters. ${ }^{9}$ High BMI values were identified as a significant risk factor for under-reporting by other authors, too. ${ }^{10-15}$ Particularly, female adolescent under-reporters compared with non-under-reporters showed different meal habits: fewer meals (about one meal less per day), less energy intake per meal (about 25\% less), more often warm meals, a shorter time span between the first and the last meal per day. They also had different nutrient patterns related to EI: higher intakes of water, protein, fibre, sodium, iron, niacin and zinc and lower intakes of added sugars than non-under-reporters. It can be speculated that these findings point to specific omissions of sweet and/or snack foods in subjects who under-report their EI. It is well known that girls are more concerned about their body image (especially weight) than boys ${ }^{16,17}$ and dieting accompanied by a fear of obesity is very common among adolescent girls. ${ }^{18,19}$ Even females with normal weight appear much more likely to generate records with no valid food intake data. ${ }^{20}$ They may use record keeping consciously or subconsciously to assist in losing weight. Thus, the records may be valid - but do not reflect the subject's usual intake.

\section{Long-term nutrient intake and body weight}

Results of studies examining associations between dietary composition and obesity in adolescence are conflicting. A cross-sectional study in adolescents ${ }^{21}$ (but more studies in children) found a positive association between fat intake and anthropometric measurements. However, studies examining long-term nutrition and body fatness mostly found no or only minor effects, ${ }^{22-25}$ including the DONALD Study. ${ }^{26}$

In the DONALD Study, a new-developed cluster method was used to investigate nutrient intake and anthropometric measures in individuals, longitudinally. ${ }^{27,28}$ For this evaluation, 228 participants aged $2-18$ y with at least 10 dietary records (repeated yearly) were available. To control for age and gender effects, dietary and anthropometric data were transformed: EI were expressed per kilogram body weight, per gram total food intake and per estimated BMR; macronutrients were calculated as percentage of EI (E\%;); BMI was recalculated as standard deviation scores (SDS) of BMI, according to IOTF reference standard. ${ }^{29}$ Clustering was based on fat intake (E\%).

Four typical clusters (C, M, H, L) differing mainly according to intraindividual mean fat intakes and intraindividual s.d. of the repeated fat intake measurements were identified (1) Constant Cluster where fat intakes mostly ranged between median and third quartile, (2) Medium Cluster where fat intakes were similar to Constant Cluster, but, with a higher intraindividual s.d., (3) High Cluster where more than $50 \%$ of subjects had fat intakes over the third quartile and (4) Low Cluster where most subjects had fat intakes lower than the 1st quartile. Mean EI did not differ between clusters, but energy density and EI:BMR did. Subjects with fat intakes lower than the first quartile (Low Cluster) had almost the highest BMI-SDS scores and those of the Constant Cluster (with quite high fat intakes), almost the lowest scores (Figure 1). In total, this statistical evaluation showed that BMI could not be explained by different longterm dietary patterns during childhood and adolescence clustered according to fat consumption.

\section{Fast food consumption patterns}

In the cross-sectional and longitudinal data analysis of the DONALD Study, no obvious differences between children and adolescents in consumption patterns for basic foods, for example bread, vegetables and milk, were observed. ${ }^{30}$ However, this was not the case for modern 'lifestyle' foods such as soft drinks and fast food that are both discussed to be associated with an increased risk for obesity in children and adolescents. In a recent evaluation, fast food consumption patterns between 1986 and 2003 in 1-18y olds were examined. Fast food dishes were defined as warm dishes eaten in or taken away from fast food restaurants or other places, for example pizzerias, cafeterias and soup kitchens. Soft drinks bought and consumed together with fast food dishes were also evaluated as 'fast food'. Fast food dishes were grouped into 'Burger' (containing meat), other 'meatbased fast food' (eg gyros, doener, fried sausage), 'fish' (fried), 'pizza', 'potatoes' (eg French fries) and 'others' (without meat, eg crepes, fried mushrooms). Beverages were grouped according to the content of caffeine (caffeinated, noncaffeinated) and sugars (nonsugar-containing 'light soft drinks'; sugar-containing 'other soft drinks'). Subjects reporting at least one fast food dish or soft drink within a 3-day record

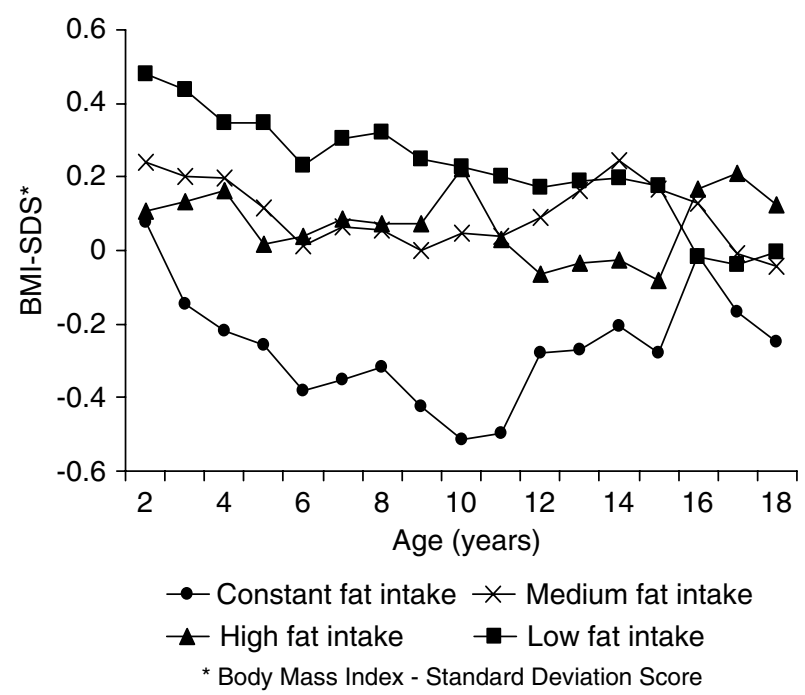

Figure 1 Differences in BMI-SDS scores according to fat consumption cluster in the DONALD Study. 
were defined as consumers and those reporting no fast food dish or soft drink as nonconsumers.

Frequency of consumption of fast food and soft drinks increased with age. Also, consumption patterns changed with age so that adolescents preferred high caloric menus (fast food dishes together with soft drinks) more than children (Figure 2a). With age, preferences increased for 'modern' fast food items like pizza and burger and decreased for classic fish and meat-based fast food (Figure $2 \mathrm{~b}$ ). There were no significant differences in food patterns according to gender in the different age groups studied here. ${ }^{31}$

Interestingly, and in contrast to other studies from the $\mathrm{USA}^{32}$ an influence of fast food consumption on BMI was
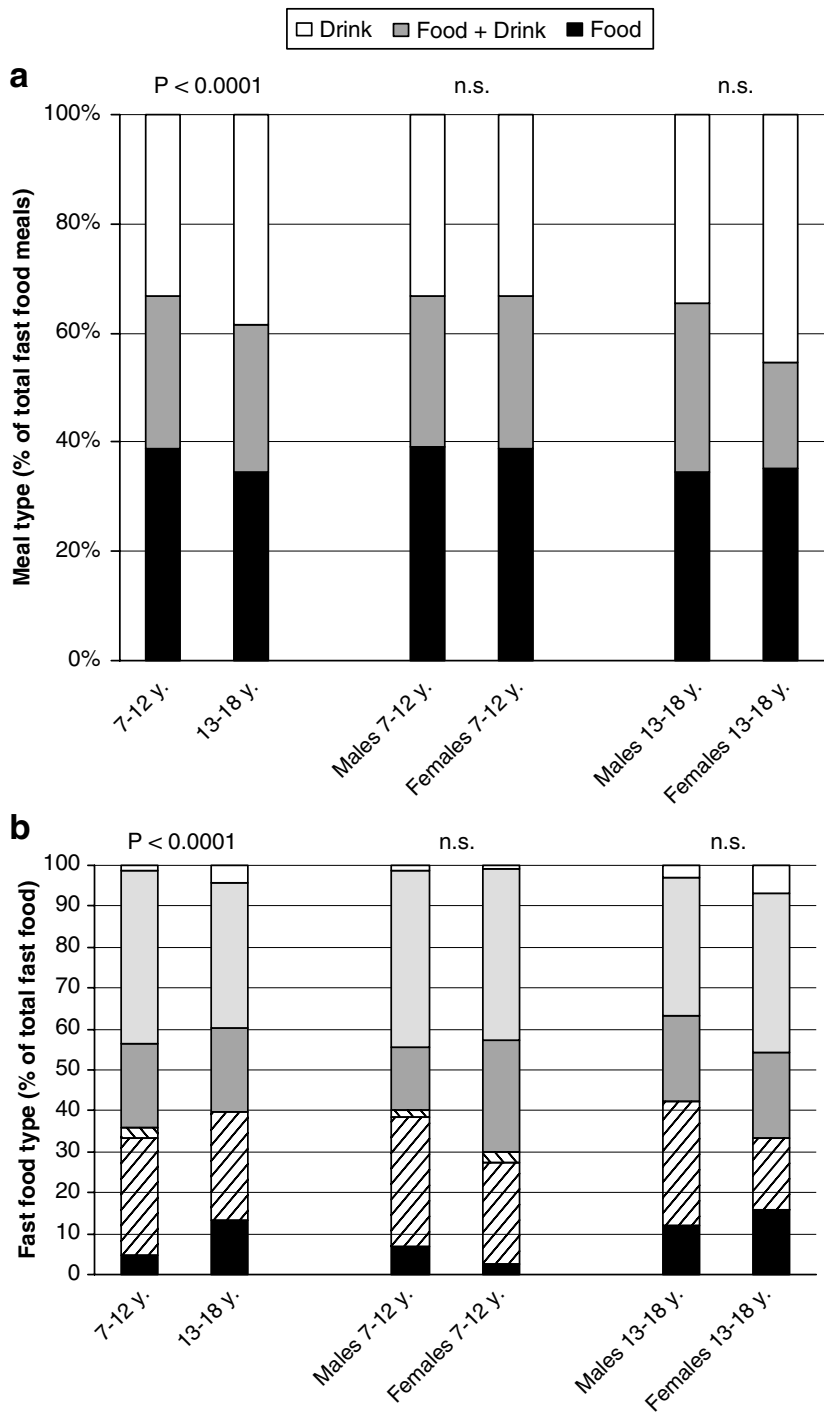

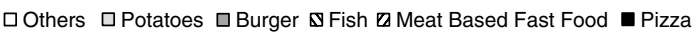

Figure 2 Preferences for fast food meal types (a) and preferences of fast food dishes (b) according to age and gender in the DONALD Study. found in the DONALD Study: consumers of fast food had higher BMI values than nonconsumers. ${ }^{30}$ Probably, food intake data based on measured consumption of various types of fast food including soft drinks is a stronger predictor of body weight than questionnaires addressing fast food restaurant visits.

\section{The Ghent experience}

In 1997, a dietary survey was carried out among adolescents from the region of Ghent in Belgium, as part of an international collaborative project on methodological issues regarding dietary assessment. ${ }^{33}$ The target population was defined as adolescents aged 13-18y attending schools in the city of Ghent in the northern Dutch-speaking part of Belgium.

The design and methodology of this survey have been described in detail elsewhere. ${ }^{34}$ In brief, 656 students from 48 classes in five schools were selected. Noneligible students $(N=91)$ were removed from further enquiries as these individuals either were on long sickness leaves or had moved to other schools. Of these 565 eligible students, 411 individuals $(72.7 \%)$ were actually willing to participate.

Dietary assessment was carried out on the basis of a 7- (consecutive) day estimated food record method, using a semistructured diary. Individuals' heights and weights were measured according to the standardised method as described in WHO, Technical Report Series $854 .^{35}$ Data on measured heights and weights were completed in the same period (within 1 week) as the dietary diary.

The data from the 7-day diary have been analysed according to two distinct approaches in order to examine the dimension of time in individuals' reporting behaviour. In a first approach, the 7 days were considered independently from each other in studying trends. In the second approach, the 7-day record was categorised into three clusters. The first cluster was set equal to the first reporting day, the second cluster consisted of the three first reporting days and the third cluster was defined as the overall period of the 7 days. For each cluster, intakes were calculated on individual level as the mean of the days under consideration.

As mentioned earlier (see the DONALD Study section) a comparison of EI with estimated BMR can be used to calculate the number of respondents in a dietary survey who might be under-reporting their EI. ${ }^{8}$ For individuals in a nondieting population, it is suggested that a ratio between EI and BMR of less than 1.35 (Cutoff 1) is unlikely to reflect habitual intake. In order to detect if the reported EI is a plausible measure of the actual diet during the measurement period, a second cutoff value (Cutoff 2 ) was introduced. The derivation of Cutoff 2 is based on the assumption of energy balance and takes into account several parameters. ${ }^{8}$ The calculation of Cutoff 2 in this study was carried out under the following conditions: data on individual level, number of days per subject, estimated values for BMR taken from 
Schofield equations ${ }^{36}$ and the lower limit of the $95 \%$ confidence interval. For the results based on 1 recording day, the value for the second cutoff was set at 0.9 , for the cluster of 3 recording days the value was set at 1.0 and for the entire 7 days, the cutoff of 1.1 was used.

The study population is assumed to be a good representation of the overall target population of adolescents in the region of Ghent. ${ }^{34}$ There were however substantially more girls than boys in the sample and there also was a slight under-representation of individuals from lower educational school segments. Among the boys, a small number of overweight adolescents were observed (7\%), while among the girls almost $15 \%$ was defined as overweight. The mean (s.d.) ratio of EI/BMR was $1.6(0.31)$ in boys and $1.4(0.33)$ in girls.

Figure 3 shows the evolution of the mean EI in the adolescent population during the 7 consecutive days of the diary and the derived mean intakes for day 1, the first 3 days and the overall 7-day recording period. In both boys and girls, there is a gradual decrease in the mean population EI from a mean value of 2836 on day 1 to $2491 \mathrm{kcal}$ on day 7 in boys and from 2086 to $1738 \mathrm{kcal}$, in girls. The 1 st and 2nd recording day were not significantly different from each other but were significantly different from all other days. The resulting decline in population mean EI as calculated over selected clusters of days is $184 \mathrm{kcal}(6.5 \%)$ in boys and 116 $(5.6 \%)$ in girls. The cluster of 1 recording day and the cluster of 3 recording days were not significantly different but they were both significantly different from the 7-day cluster.

In a bivariate model including an indicator of body fatness, that is, BMI expressed as percentage of the percentile cut-off points according to Cole's methodology, ${ }^{29}$ no significant interaction was observed between the effect of time and this indicator of body fatness, suggesting that overweight individuals and normal weight individuals in this age group present similar types of time-dependent reporting bias for EI.

Figures 4 and 5 show analogous graphical presentation for total fat intake and for total carbohydrate intake, expressed as absolute intake for boys and girls separately. Intake of fat and carbohydrate expressed as absolute values decreases gradually over the 7-day recording period. The difference between mean intakes on days 1 and 7 amounts to $9.5 \mathrm{~g} / \mathrm{day}$ for fat and $59.3 \mathrm{~g} /$ day for carbohydrate in boys and to $12.8 \mathrm{~g} /$ day for fat and $47.8 \mathrm{~g} /$ day for carbohydrate in girls. Expressed as a proportion of the absolute intake, these differences are somewhat lower for fat than to carbohydrates, suggesting that reporting bias for foods with high fat content is somewhat less pronounced. Fat and carbohydrate intake relative to total EI shows a somewhat different overall picture. Both for fat and carbohydrate, the mean proportional EI remains relatively stable, in view of the declining EI (data not shown).

Tables 1 and 2 show the changes in the estimated proportions of individuals that are under-reporting according to the criteria described before. Based on the 7 consecutive days, the proportion of adolescents below the cutoff of 0.9 increased from $7.9 \%$ on the 1 st recording day to $19.9 \%$ on the 7 th day. Comparing the clusters of days $(1 / 3 / 7)$ the proportion of subjects who were defined as under-reporters (using the appropriate cut-offs for each category, see above) increases from $7.9 \%$ in the 1st-day cluster to $15.5 \%$ in the 7 th-day cluster. It should be noted that these cutoff values of the EI:BMR ratio were based on calculations in adults. However, a recalculation for adolescents would not substantially change the conclusions regarding trends in under-reporting.

These findings suggest an important impact of survey duration on the reported intake of energy, fat and carbohydrates. The observed decline in reported population mean energy and energy yielding macronutrients over the 7-day survey period is compatible with the increasing proportion of under-reporters, although theoretically these two phenomena can be quite independent from each other. However, the stability of the confidence intervals strongly suggests that the declining trend affects the population as a whole and that the shift in the population distribution gradually 'pushes' a higher proportion of the population across the 'under-reporting edge'. This observation also raises the question of whether respondents are-on population level-reporting normally during the first 2 days or are perhaps over-reporting during the first days and then gradually return to adequate reporting. The latter scenario is however less plausible in view of the proportion of under-reporters detected by the cutoffs. However, the reality underlying these observations could be rather more complicated than described here. Overall, these findings could be compatible with a hypothetical participants' motivation curve, falling off with increasing number of days of data collection, especially if these days are consecutive. ${ }^{37}$

The different clusters of reporting days in our study show that the clusters of 1 and 3 days do not show significant differences in mean intake of macronutrients. The percentage of under-reporters within this time window also remains stable around $10 \%$ for all adolescents. For many purposes in the context of studying diet-related diseases, it has been recommended in the literature that more than one record per individual be collected. ${ }^{38}$ Different studies have shown that 3 record days were better than 1-day estimates of individual intake. ${ }^{39}$ Lambe et $a l^{40}$ found that 3 days provided a much better reflection of more long-term intakes of food items than 1 day. The number of records is described to be at least two, assuming that the sample size is large enough. ${ }^{41}$ Different researchers recommended using nonconsecutive days when multiple records were used. ${ }^{41-43}$

\section{The Alimentación y Valoración del Estado Nutricional en Adolescentes (AVENA) Study}

The AVENA Study is a Spanish cross-sectional multicentre survey carried out between 2000 and 2002. The main 
a

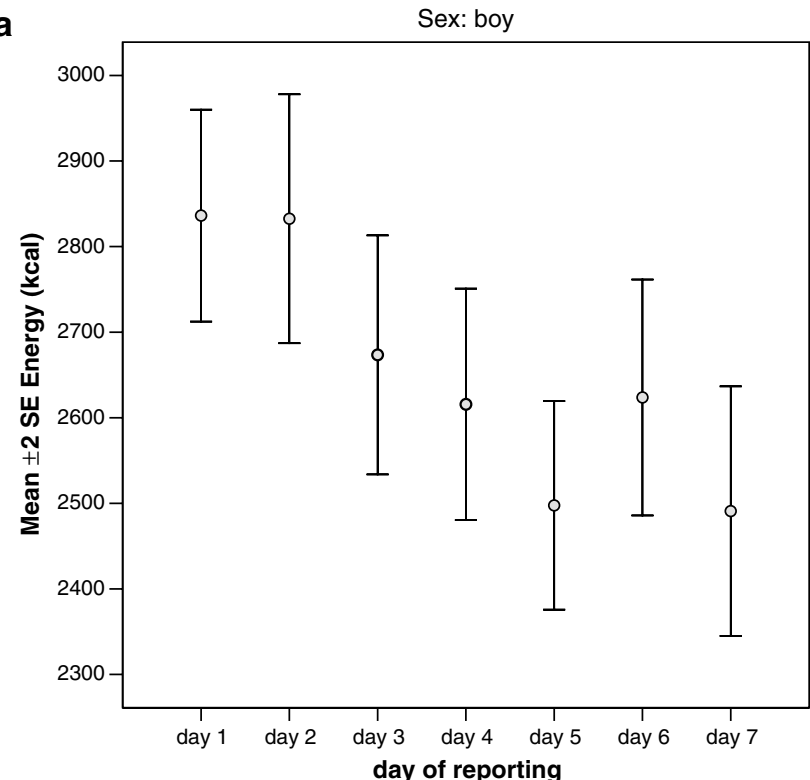

b

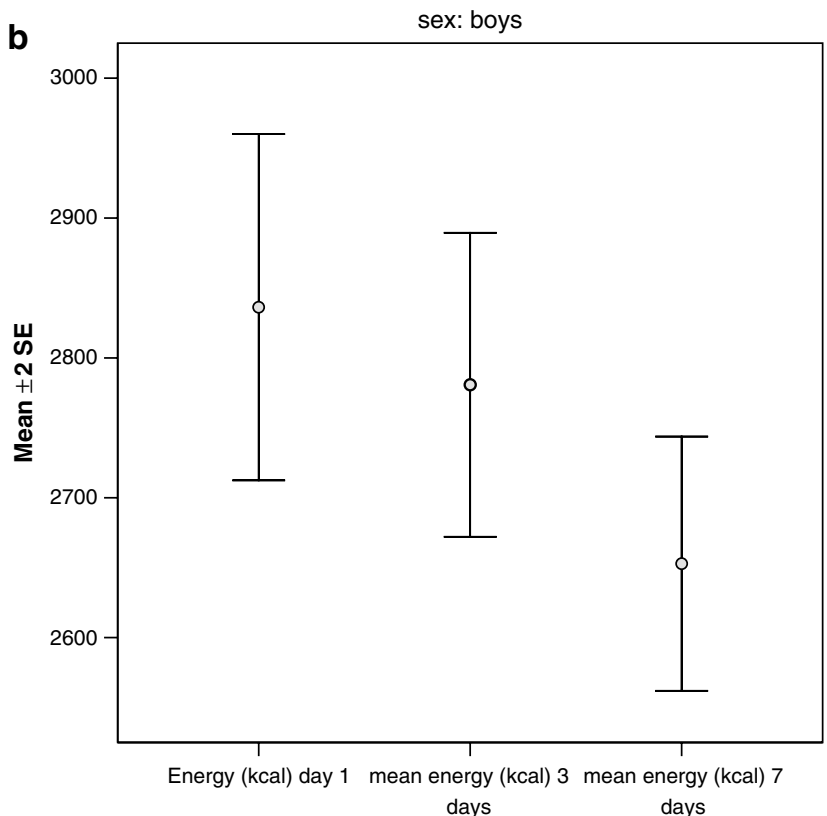

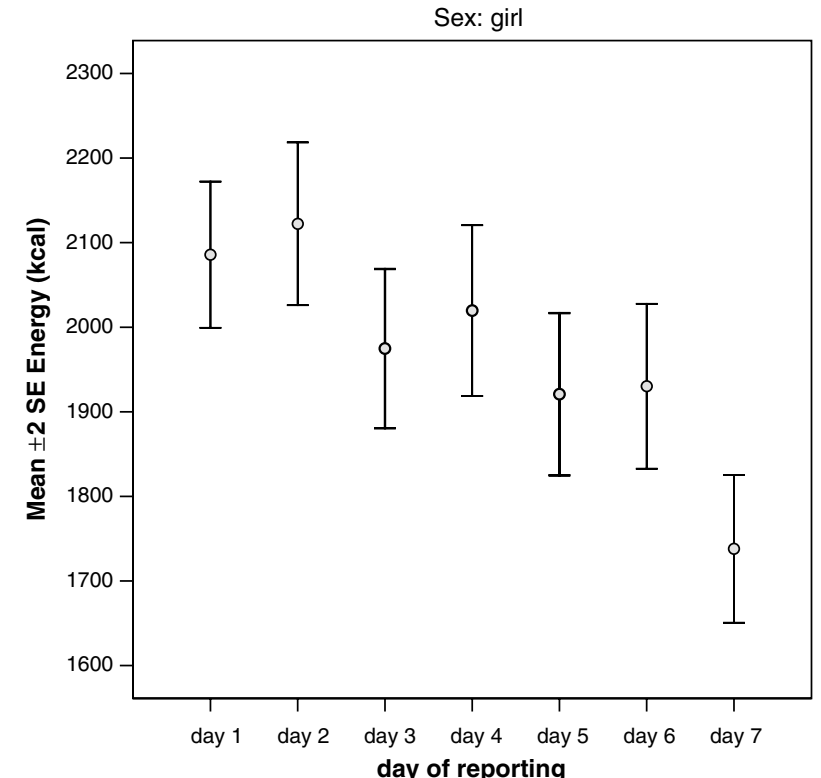

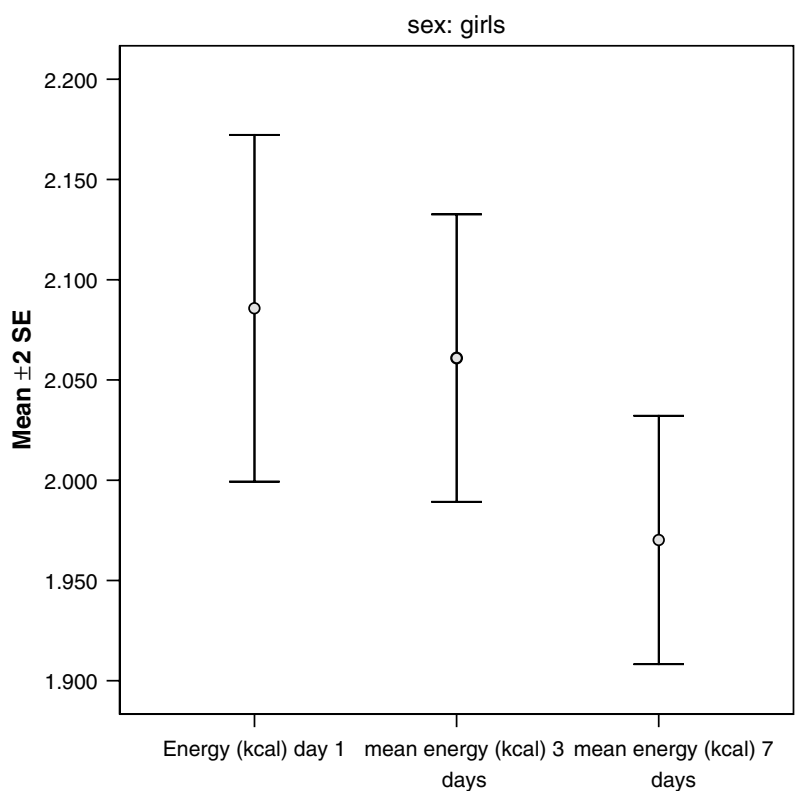

Figure 3 The evolution of the mean ( \pm s.e.) energy intake over the 7 consecutive days of the diary (a) and the derived mean intakes over a 1- day, a 3- day and a 7- day recording period (b) in boys and girls.

objective of the AVENA Study was to obtain data about health status, dietary and behaviour habits and the nutritional-metabolic situation of a representative sample of adolescents that were lacking at the time the study was planned. Specifically, the following magnitudes have been studied: (a) dietary intake, food habits and nutrition knowledge; (b) daily physical activity and personal approach; (c) physical condition; (d) anthropometry and body composition; (e) haematological and biochemical study; (f) genotypic profile of cardiovascular risk factors; (g) immune function profile related to nutritional status and (h) psychological profile. ${ }^{44}$

The AVENA Study has been possible due to the coordinated activity of five research groups in five Spanish cities (Granada, Madrid, Murcia, Santander and Zaragoza). Strict standardisation and harmonisation of the field work and the centralised analysis of blood samples and evaluation of questionnaires have tried to avoid from the beginning the huge amount of confusing variables that appear when data from isolated studies are compared. 

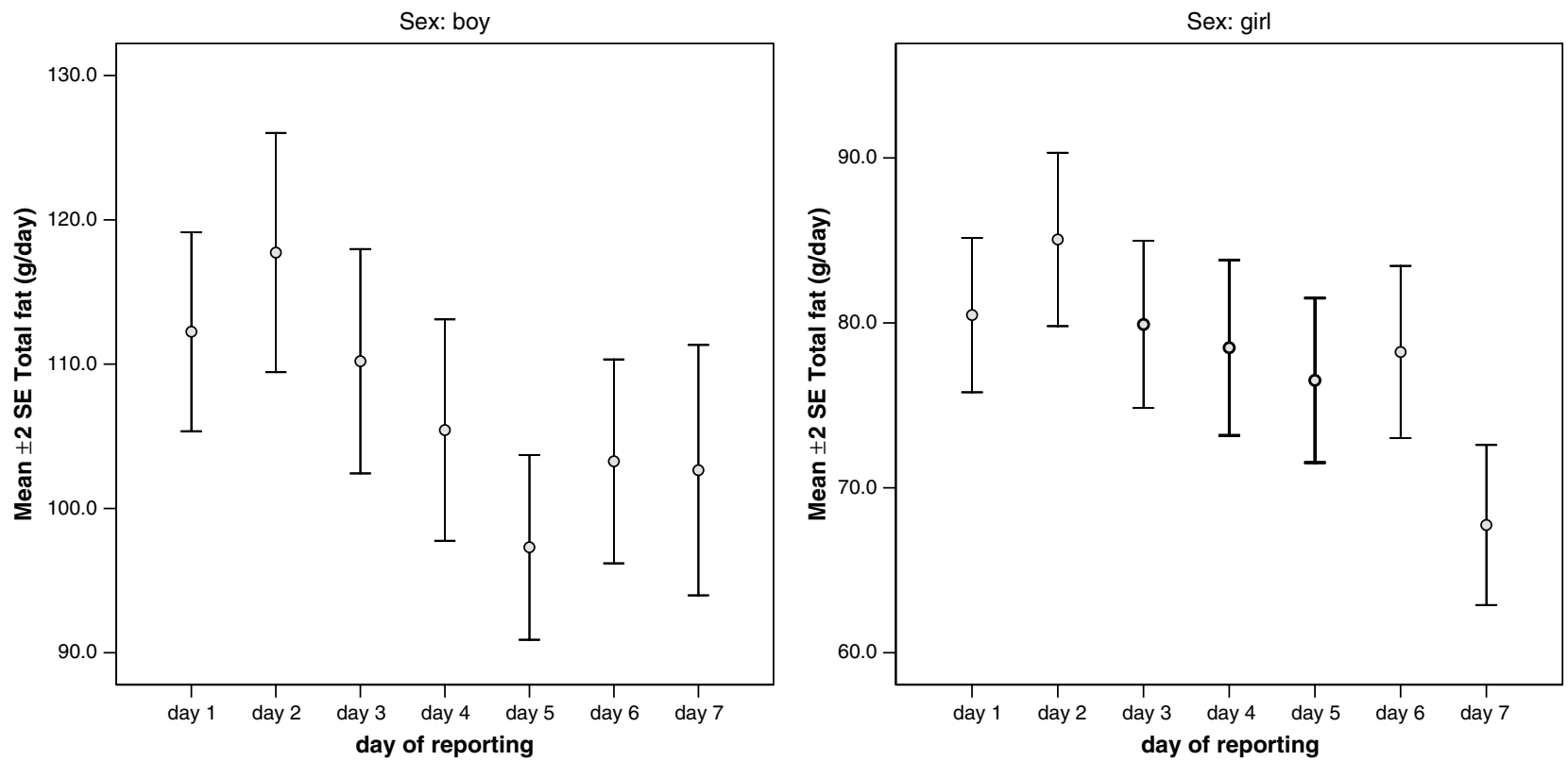

Figure 4 The evolution of the mean ( \pm s.e.) fat intake over the 7 consecutive days of the diary expressed as $\mathrm{g} /$ day in boys and girls.
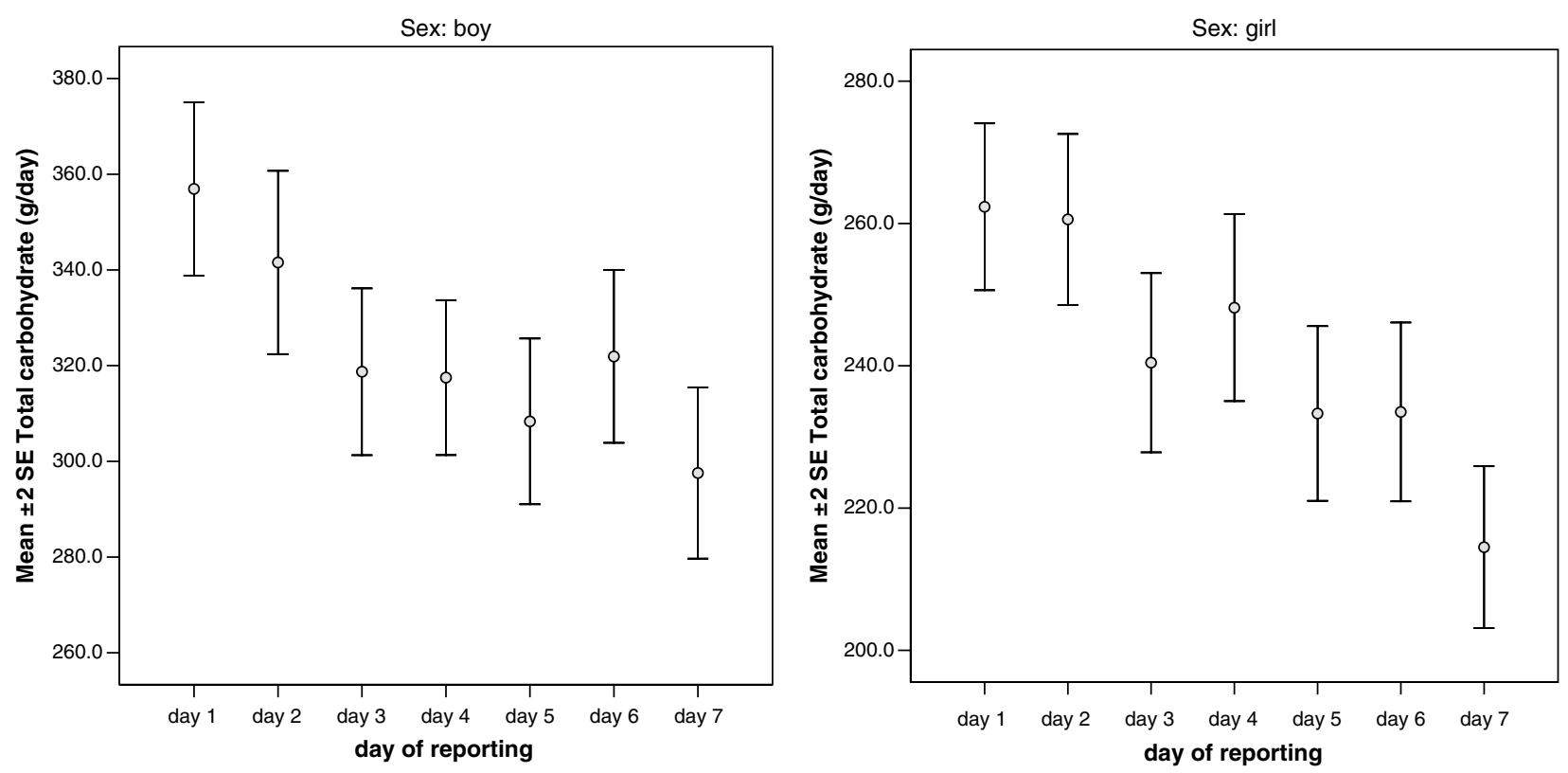

Figure 5 The evolution of the mean ( \pm s.e.) carbohydrate intake over the 7 consecutive days of the diary expressed as $\mathrm{g} /$ day in boys and girls.

A fundamental component of a healthy diet is to eat a balanced breakfast, which is important for nutritional adequacy. A good breakfast can contribute to a healthy diet rich in carbohydrates and micronutrients. ${ }^{45,46}$ In fact, having an adequate breakfast has been related to both physical and cognitive function and better performance at school in children and adolescents. The breakfast habits have changed in the course of time and the number of breakfast skippers has increased during the last $30 \mathrm{y}$. Especially, female and older adolescents tend to omit the morning meal. ${ }^{47}$ Various reasons for skipping breakfast such as lack of time or not being hungry in the morning can be observed. ${ }^{48}$ Cho et $a l^{49}$ have also observed that some types of breakfast, like meat and eggs and breakfast skippers were associated with the highest BMI values.

For the results presented in this paper, a sample of 1282 adolescents (572 males, 710 females) aged 13 to $18.5 \mathrm{y}$ from Santander, Zaragoza and Granada were analysed. The 
Table 1 The proportion of individuals that are underreporting (EI/BMR $<0.9$ ) according to sex and recording day. The Ghent experience

\begin{tabular}{lrrrrr}
\hline & \multicolumn{2}{c}{$\begin{array}{c}\text { Boys } \\
\text { El/BMR }\end{array}$} & & \multicolumn{2}{c}{$\begin{array}{c}\text { Girls } \\
\text { El/BMR }\end{array}$} \\
\cline { 2 - 3 } & $<0.9$ & $\geq 0.9$ & $<0.9$ & $\geq 0.9$ \\
\cline { 2 - 5 } & 3.1 & 96.9 & 10.8 & 89.2 \\
Day 1 & 3.1 & 96.9 & 10.8 & 89.2 \\
Day 2 & 6.2 & 93.8 & 15.1 & 84.9 \\
Day 3 & 7.8 & 92.2 & 16.0 & 84.0 \\
Day 4 & 9.3 & 90.7 & 18.9 & 81.1 \\
Day 5 & 10.1 & 89.9 & 20.3 & 79.7 \\
Day 6 & 9.3 & 90.7 & 26.4 & 73.6 \\
Day 7 & & & &
\end{tabular}

Table 2 Proportion of individuals that are underreporting according to sex and cluster of recording days. The Ghent experience

\begin{tabular}{|c|c|c|c|c|}
\hline & \multicolumn{2}{|c|}{ Boys } & \multicolumn{2}{|c|}{ Girls } \\
\hline & $\begin{array}{l}\text { Under- } \\
\text { reporting }\end{array}$ & $\begin{array}{l}\text { Normal } \\
\text { reporting }\end{array}$ & $\begin{array}{l}\text { Under- } \\
\text { reporting }\end{array}$ & $\begin{array}{l}\text { Normal } \\
\text { reporting }\end{array}$ \\
\hline $\begin{array}{l}\text { Cluster of } 1 \text { day } \\
(\mathrm{EI} / \mathrm{BMR}<0.9)\end{array}$ & 3.1 & 96.9 & 10.8 & 89.2 \\
\hline $\begin{array}{l}\text { Cluster of } 3 \text { days } \\
(\text { El/BMR }<1.006)\end{array}$ & 3.9 & 96.1 & 14.2 & 85.8 \\
\hline $\begin{array}{l}\text { Cluster of } 7 \text { days } \\
(\text { El/BMR }<1.1)\end{array}$ & 7.8 & 92.2 & 20.3 & 79.7 \\
\hline
\end{tabular}

population was selected by means of a multiple-step, simple random sampling, taking into account first the location (Granada, Madrid, Santander, Zaragoza and Murcia) and then by random assignment of the schools within each city. Sample size was stratified by age and sex.

Breakfast habits were analysed by means of a specific question included in a full questionnaire. This form was specifically designed by the research team for the study and validated in the AVENA pilot study. ${ }^{44}$ The question contained 12 alternatives for breakfast components, which were 10 foods that are typical of a Spanish breakfast, such as milk, toast, biscuits or fruit. One 'other-field' was included in which unlisted components could be itemised. Finally, participants could indicate that they had no breakfast at all. The task was to mark the components of one's own habitual breakfast. The 10 foods were divided into five food groups: milk (milk and cocoa), carbohydrates (toasts, granola and cereals), fruit (fruits and juices), pastries (biscuits and pastries) and coffee.

The percentage of adolescents skipping breakfast was higher in females $(8.6 \%)$ than in males $(3.5 \%, P<0.001)$. A marked age-effect on female breakfast skippers should be pointed out, as at age $13 \mathrm{y}$ only $1.7 \%$ of the girls skipped breakfast and at age $17-18.5$ y already $13.5 \%$ did $(P<0.01)$. The proportion of adolescents consuming milk, carbohydrates, fruits and pastries was higher in males than in females (Figure 6). These differences by sex have also been observed in other studies. In studies from the USA ${ }^{50}$ and Sweden, ${ }^{51,52}$ there were more breakfast skippers among females than among males. These differences were even greater than in the AVENA Study. When we compared BMI mean levels between adolescents skipping and not skipping breakfast, in general, we observed higher BMI values in those skipping breakfast when compared with those not skipping breakfast, but differences were statistically significant in males at $15 \mathrm{y}$ and in females at 14 and $17 \mathrm{y}$ (Table 3 ). When we analysed BMI according to breakfast food consumption (Tables 4 and 5), we observed that adolescents who avoid some food groups for breakfast had higher BMI values. The results were statistically significant for carbohydrates (at ages 13,14 and $17 \mathrm{y}$ ), fruits (at $13 \mathrm{y}$ ) and pastries (at 13 and $15 \mathrm{y}$ ) in males, and for milk (at 13y), fruits (at 16 and $17 \mathrm{y}$ ) and pastries (at13y) in females.

We have not investigated the reasons for skipping breakfast, but other studies observed that the reasons were lack of time for the preparation and consumption and concerns about excess body weight. ${ }^{53,54}$ However, there is a statistically significant influence of socio-economic status on

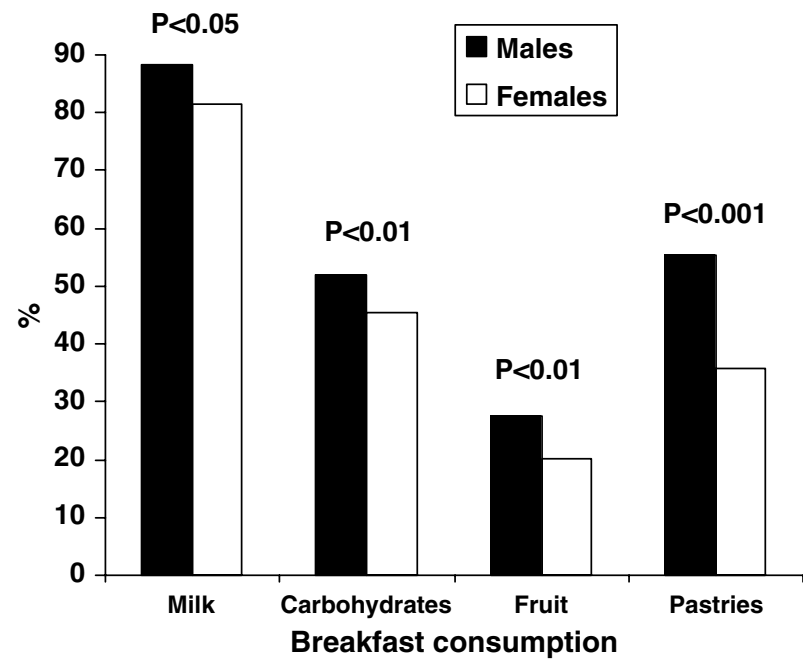

Figure 6 Breakfast patterns by gender in adolescents from the AVENA Study.

Table 3 Body mass index in Spanish adolescents skipping or not skipping breakfast. The AVENA Study

\begin{tabular}{lccccc}
\hline & \multicolumn{2}{c}{ Males } & & \multicolumn{2}{c}{ Females } \\
\cline { 2 - 3 } \cline { 5 - 6 } Age (y) & $\begin{array}{c}\text { Yes } \\
\text { Mean (s.d.) }\end{array}$ & $\begin{array}{c}\text { No } \\
\text { Mean (s.d.) }\end{array}$ & & $\begin{array}{c}\text { Yes } \\
\text { Mean (s.d.) }\end{array}$ & $\begin{array}{c}\text { No } \\
\text { Mean (s.d.) }\end{array}$ \\
\hline 13 & - & - & & - & - \\
14 & $24.07(5.47)$ & $21.53(3.35)$ & & $23.46(6.70)$ & $21.21(3.26)^{*}$ \\
15 & $24.21(7.28)$ & $22.52(3.56)^{*}$ & & $22.64(2.71)$ & $21.40(2.77)$ \\
16 & $22.44(2.54)$ & $21.87(3.03)$ & & $22.63(2.36)$ & $21.63(2.88)$ \\
17 & $21.56(0.46)$ & $22.84(3.08)$ & & $23.11(4.05)$ & $21.60(2.93)^{*}$ \\
\hline$* P<0.05$. & & & &
\end{tabular}


Table 4 Body mass index by breakfast food consumption in male adolescents. The AVENA Study

\begin{tabular}{|c|c|c|c|c|c|c|c|c|}
\hline \multirow[b]{2}{*}{ Age (y) } & \multicolumn{2}{|c|}{ Milk } & \multicolumn{2}{|c|}{ Carbohydrates } & \multicolumn{2}{|c|}{ Fruit } & \multicolumn{2}{|c|}{ Pastries } \\
\hline & $\begin{array}{c}\text { Yes } \\
\text { Mean (s.d.) }\end{array}$ & $\begin{array}{c}\text { No } \\
\text { Mean (s.d.) }\end{array}$ & $\begin{array}{c}\text { Yes } \\
\text { Mean (s.d.) }\end{array}$ & $\begin{array}{c}\text { No } \\
\text { Mean (s.d.) }\end{array}$ & $\begin{array}{c}\text { Yes } \\
\text { Mean (s.d.) }\end{array}$ & $\begin{array}{c}\text { No } \\
\text { Mean (s.d.) }\end{array}$ & $\begin{array}{c}\text { Yes } \\
\text { Mean (s.d.) }\end{array}$ & $\begin{array}{c}\text { No } \\
\text { Mean (s.d.) }\end{array}$ \\
\hline 13 & $20.33(3.54)$ & $19.64(4.32)$ & $19.84(3.35)$ & $21.06(3.87)^{*}$ & $19.51(2.83)$ & $20.52(3.76)^{*}$ & $19.72(2.76)$ & $20.86(4.21)^{* *}$ \\
\hline 14 & 21.55 (3.72) & $22.71(5.24)$ & $20.86(3.36)$ & $22.65(4.25)^{\star}$ & $23.25(4.40)$ & $21.14(3.56)$ & $22.09(4.14)$ & $21.31(3.63)$ \\
\hline 15 & $22.34(3.53)$ & $24.04(4.11)$ & $22.30(3.69)$ & $22.83(3.58)$ & $23.19(4.32)$ & $22.30(3.31)$ & $22.27(3.06)$ & $22.81(4.08)^{\star}$ \\
\hline 16 & $21.98(3.05)$ & $21.39(2.66)$ & $22.02(3.31)$ & $21.76(2.62)$ & $21.40(2.79)$ & $22.08(3.04)$ & $21.64(2.74)$ & $22.33(3.28)$ \\
\hline 17 & $22.64(2.90)$ & $23.72(3.71)$ & $21.61(2.14)$ & $23.41(3.25)^{*}$ & $23.26(3.10)$ & $22.51(2.98)$ & $22.74(2.66)$ & $22.89(3.59)$ \\
\hline
\end{tabular}

${ }^{*} P<0.05,{ }^{* *} P<0.001$ when comparing Yes $v s$ no in the same age and pattern category.

Table 5 Body mass index by breakfast food consumption in female adolescents. The AVENA Study

\begin{tabular}{|c|c|c|c|c|c|c|c|c|}
\hline \multirow[b]{2}{*}{ Age (y) } & \multicolumn{2}{|c|}{ Milk } & \multicolumn{2}{|c|}{ Carbohydrates } & \multicolumn{2}{|c|}{ Fruit } & \multicolumn{2}{|c|}{ Pastries } \\
\hline & $\begin{array}{c}\text { Yes } \\
\text { Mean (s.d.) }\end{array}$ & $\begin{array}{c}\text { No } \\
\text { Mean (s.d.) }\end{array}$ & $\begin{array}{c}\text { Yes } \\
\text { Mean (s.d.) }\end{array}$ & $\begin{array}{c}\text { No } \\
\text { Mean (s.d.) }\end{array}$ & $\begin{array}{c}\text { Yes } \\
\text { Mean (s.d.) }\end{array}$ & $\begin{array}{c}\text { No } \\
\text { Mean (s.d.) }\end{array}$ & $\begin{array}{c}\text { Yes } \\
\text { Mean (s.d.) }\end{array}$ & $\begin{array}{c}\text { No } \\
\text { Mean (s.d.) }\end{array}$ \\
\hline 13 & $21.15(3.40)$ & $23.37(5.36)^{*}$ & $21.37(3.69)$ & $21.32(3.63)$ & $20.99(2.51)$ & $21.45(3.90)$ & $20.72(2.37)$ & $21.83(4.34)^{\star \star}$ \\
\hline 14 & $21.11(3.26)$ & $22.55(4.44)$ & $21.24(3.35)$ & $21.34(3.55)$ & $21.82(3.30)$ & $21.20(3.48)$ & $20.70(2.79)$ & $21.63(3.74)$ \\
\hline 15 & $21.41(2.87)$ & $21.96(2.42)$ & $21.30(3.01)$ & $21.75(2.54)$ & $21.89(2.05)$ & $21.42(2.96)$ & $21.15(2.26)$ & $21.75(3.04)$ \\
\hline 16 & $21.71(2.99)$ & $21.67(2.27)$ & $21.89(3.18)$ & $21.55(2.49)$ & $20.82(1.73)$ & $21.96(3.04)^{*}$ & $21.35(2.49)$ & $21.89(3.02)$ \\
\hline 17 & $21.62(2.96)$ & $22.17(3.43)$ & $22.04(2.96)$ & $21.53(3.16)$ & $21.17(2.49)$ & $21.92(3.22)^{*}$ & $21.38(2.82)$ & $21.91(3.18)$ \\
\hline
\end{tabular}

${ }^{*} P<0.05,{ }^{* *} P<0.01$ when comparing Yes $v s$ no in the same age and pattern category.

breakfast habits, as the percentage of adolescents having an 'adequate' breakfast increases as the SES increases (from 11.2 to $27.6 \% ; P<0.05)$.

In coincidence with our data, an inverse relationship has been found between BMI and breakfast consumption in other studies. ${ }^{55-58}$ Breakfast eaters tend to have a lower BMI than breakfast skippers, ${ }^{56}$ and obese individuals are more likely to skip breakfast or consume less energy at breakfast. ${ }^{57,58}$ Breakfast skipping can lead to overeating later in the day. ${ }^{59}$ In contrast, eating breakfast is associated with increased eating frequency and this may in turn promote less efficient energy utilisation by increasing dietary-induced thermogenesis, leading to a lower BMI. ${ }^{60}$ Eating some foods for breakfast, like carbohydrates, seems to be associated with a significantly lower BMI than skipping breakfast or eating other food items ${ }^{49}$ as we observed in our adolescents.

\section{Comments and conclusions}

The relationship between diet and obesity should focus not only on energy and macronutrient intake, but also on dietary patterns. Traditionally, the focus has been on energy balance and percentage contribution of macronutrients, but the results are very controversial, especially for dietary fat and proteins. $^{61}$ As a result of several shortcomings in traditional nutrient-based diet and disease analysis, the focus has shifted from this type of analysis to one describing food intake patterns. ${ }^{62}$ Such analysis takes into account the complex combination of foods in a diet. The effect of such food-based defined dietary patterns might be more closely related to obesity than a single nutrient or food. To describe dietary intake and food habits in overweight and obese individuals will be relevant not only in terms of causality of obesity, but also in terms of the knowledge and understanding of the eating behaviour with regard to body weight regulation in a modern affluent society.

In adults, several epidemiologic studies examined the association of dietary patterns and excessive body weight. ${ }^{63-65}$ These food-based dietary patterns have been established on the basis of several statistical methodologies. Another approach to assessing an individual's diet is to score it with a set of criteria to produce a composite index of diet quality. A low Healthy Eating Index (HEI) was associated with overweight and obesity; there was a graded increase in the odds ratio of obesity across the HEI category after adjusting for age, gender, race/ethnicity, physical activity, smoking, alcohol use, income and education. ${ }^{66}$

Assessment of dietary intake faces many problems, both related to the true nature of variation in an individual's diet and to a number of potential sources of error linked to the measurement instrument and to the reporting subject. Depending on the type of research and the dietary assessment instruments chosen accordingly, the sources of error may interact with each other in different ways. Some of the sources of error described in the past, have a relatively stable and predictable character and can to some extent be tackled by anticipatory measures. For instance, the number of days required to estimate the intake of specific nutrients with a reasonable precision has been described extensively and this 
can a priori be incorporated in a protocol for planning research. Other sources of error are however more fluctuating and likely to vary much more across cultures andwithin cultures - across subgroups of the population, for example lower social class subjects, younger age $v s$ older age, etc.

A number of validation studies have shown that misreporting is a major problem in dietary surveys of children and adolescents and so all the dietary data collected should be interpreted and evaluated with caution. In addition, each country uses a different set of food composition data. This can make comparisons between countries difficult and inaccurate. So, there are uncertainties over the true nutrient intakes of children and adolescents across Europe. There are also insufficient data on status to be able to draw any conclusions about the nutritional quality of the diets of European children and adolescents.

Obviously, dietary habits are influenced by age because physiological requirements as well as environmental influences are changing with age. Whereas the family environment strongly determines dietary intake and dietary habits in young children and thus risk of obesity, peer groups, food marketing and lifestyle are gaining increasing influence with age in older children and adolescents. Additionally, dietary intakes may change with time, for example due to dietary information or prevention campaigns. To examine potential influences of age on dietary intake and body weight, consumption data throughout all age groups in childhood and in adolescence are necessary. For different ages, some very specific problems have to be overcome in view of the changes in ability to report dietary habits, changes in cognitive skills and changing social contexts and behaviours. Recently, Huang et $a l^{67}$ pointed out that excluding implausible dietary reports is necessary for discerning dietary associations with BMI percentile. EI and meal, but not snack patterns could play a quantitatively greater role in weight regulation as children get older.

Regarding food and lifestyle habits, adolescents have particular food choices and meal habits compared to younger children and adults. Although all around Europe there are different cultural eating patterns, literature dealing with adolescents shows that globalisation is affecting adolescents in a similar way. One common finding is frequent skipping of meals, particularly breakfast. ${ }^{51}$ The main inadequate food consumption patterns are low consumption of fruits and vegetables, frequent snacking, with snack foods generally of a high fat/high sugar content. ${ }^{51,68}$

A 24-h recall method was selected by the EFCOSUM Group, as the best and most cost-effective method. To obtain the population distribution of usual intake, correction for within-subject variation is necessary. To this end repeated $24-\mathrm{h}$ recalls are needed. A food classification system is needed to make food consumption data comparable at the food level. Foods can only be made comparable at the 'raw edible' ingredient level.
Dietary and nutrient intake data in the HELENA project will be obtained regarding these EFCOSUM proposals. The main objective is to develop, validate and establish innovative, standardised instruments and procedures for the assessment of dietary habits of adolescents across Europe to allow a comprehensive dietary characterisation by nutrient intakes, food consumption, meal patterns and nutritional knowledge and eating attitudes. Data from HELENA (food and nutrient intakes, body weight) might be a basis for developing complex approaches like Healthy Eating Indices.

\section{Acknowledgements}

The HELENA Study took place with the financial support of the European Community Sixth RTD Framework Programme (Contract FOOD-CT-2005-007034). The content of this article reflects only the author's views and the Community is not liable for any use that may be made of the information contained therein. The DONALD Study is supported by the Ministry of Science and Research, North Rhine-Westphalia, Germany. The study in Ghent was financially supported by the National Fund for Scientific Research (fund no. 31557898) and by a grant from Kellogg's Benelux. The AVENA Study was supported by the Spanish Ministry of Health, Grant FIS 00/0015 and Red de Centros RCESP C03/ 09, CSD Grants 05/UPB32/0, 109/UPB31/03 and 13/UPB20/ 04, the Spanish Ministry of Education (AP2003-2128) and grants from Panrico SA, Madaus SA and Procter and Gamble SA.

\section{References}

1 Moreno LA, Sarría A, Fleta J, Rodríguez G, Bueno M. Trends in body mass index and overweight prevalence among children and adolescents in the region of Aragón (Spain) from 1985 to 1995. Int J Obes Relat Metab Disord 2000; 24: 925-931.

2 Moreno LA, Mesana MI, Fleta J, Ruiz JR, González-Gross MM, Sarría A, Marcos A, Bueno M, the AVENA Study Group. Overweight, obesity and body fat composition in Spanish adolescents. The AVENA Study. Ann Nutr Metab 2005; 49: 71-76.

3 Ogden CL, Flegal KM, Carroll MD, Johnson CL. Prevalence and trends in overweight among US children and adolescents, 19992000. JAMA 2002; 288: 1728-1732.

4 Lambert J, Agostoni C, Elmadfa I, Hulshof K, Krause E, Livingstone B, Socha P, Pannemans D, Samartín S. Dietary intake and nutritional status of children and adolescents in Europe. $\mathrm{Br} J$ Nutr 2004; 92 (Suppl. 2): S147-S211.

5 Rockett HR, Berkey CS, Colditz GA. Evaluation of dietary assessment instruments in adolescents. Curr Opin Clin Nutr Metab Care 2003; 6: 557-562.

6 Kroke A, Manz F, Kersting M, Remer T, Sichert-Hellert W, Alexy U, Lentze M. The DONALD Study: history, current status and future perspectives. Eur J Nutr 2004; 43: 45-54.

7 Kersting M, Sichert-Hellert W, Lausen B, Alexy U, Manz F, Schoch G. Energy intake of 1 to 18 year old German children and adolescents. Z Ernahrungswiss 1998; 37: 47-55.

8 Goldberg GR, Black AE, Jebb SA, Cole TJ, Murgatroyd PR, Coward WA, Prentice AM. Critical evaluation of energy intake data using fundamental principles of energy physiology: 1 . Derivation of cut-off limits to identify under-recording. Eur J Clin Nutr 1991; 45: $569-581$ 
9 Sichert-Hellert W, Kersting M, Schoch G. Underreporting of energy intake in 1 to 18 year old German children and adolescents. Z Ernahrungswiss 1998; 37: 242-251.

10 Bandini LG, Schoeller DA, Cyr HN, Dietz WH. Validity of reported energy intake in obese and nonobese adolescents. Am J Clin Nutr 1990; 52: 421-425.

11 Livingstone MB, Prentice AM, Coward WA, Strain JJ, Black AE, Davies PS, Stewart CM, McKenna PG, Whitehead RG. Validation of estimates of energy intake by weighed dietary record and diet history in children and adolescents. Am J Clin Nutr 1992; 56: 2935.

12 Price GM, Paul AA, Cole TJ, Wadsworth ME. Characteristics of the low-energy reporters in a longitudinal national dietary survey. Br J Nutr 1997; 77: 833-851.

13 Bratteby LE, Sandhagen B, Fan H, Enghardt H, Samuelson G. Total energy expenditure and physical activity as assessed by the doubly labeled water method in Swedish adolescents in whom energy intake was underestimated by 7 -d diet records. Am J Clin Nutr 1998; 67: 905-911.

14 Champagne CM, Baker NB, DeLany JP, Harsha DW, Bray GA. Assessment of energy intake underreporting by doubly labeled water and observations on reported nutrient intakes in children. J Am Diet Assoc 1998; 98: 426-433.

15 Livingstone MB, Robson PJ. Measurement of dietary intake in children. Proc Nutr Soc 2000; 59: 279-293.

16 Moore DC. Body image and eating behavior in adolescents. J Am Coll Nutr 1993; 12: 505-510.

17 Andersen LF, Nes M, Sandstad B, Bjorneboe GE, Drevon CA. Dietary intake among Norwegian adolescents. Eur J Clin Nutr 1995; 49: 555-564.

18 Flynn MA. Fear of fatness and adolescent girls: implications for obesity prevention. Proc Nutr Soc 1997; 56: 305-317.

19 Maloney MJ, McGuire J, Daniels SR, Specker B. Dieting behavior and eating attitudes in children. Pediatrics 1989; 84: 482-489.

20 Mela DJ, Aaron JI. Honest but invalid: what subjects say about recording their food intake. J Am Diet Assoc 1997; 97: 791-793.

21 Garaulet M, Martinez A, Victoria F, Perez-Llamas F, Ortega RM, Zamora S. Difference in dietary intake and activity level between normal-weight and overweight or obese adolescents. J Pediatr Gastroenterol Nutr 2000; 30: 253-258.

22 Berkey CS, Rockett HR, Field AE, Gillman MW, Frazier AL, Camargo CA, Colditz GA. Activity, dietary intake, and weight changes in a longitudinal study of preadolescent and adolescent boys and girls. Pediatrics 2000; 105: E56.

23 Cavadini C, Siega-Riz A, Popkin BM. US adolescent food intake trends from 1965 to 1996. Arch Dis Child 2000; 83: 18-24.

24 Troiano RP, Briefel RR, Carroll MD, Bialostosky K. Energy and fat intakes of children and adolescents in the United States: data from the national health and nutrition examination surveys. Am J Clin Nutr 2000; 72: 1343S-1353S.

25 Magarey AM, Daniels LA, Boulton TJ, Cockington RA. Does fat intake predict adiposity in healthy children and adolescents aged 2-15 y? A longitudinal analysis. Eur J Clin Nutr 2001; 55: $471-481$.

26 Remer T, Dimitriou T, Kersting M. Does fat intake explain fatness in healthy children? Eur J Clin Nutr 2002; 56: 1046-1047.

27 Alexy U, Sichert-Hellert W, Kersting M, Schultze-Pawlitschko V. Pattern of long-term fat intake and BMI during childhood and adolescence - results of the DONALD Study. Int J Obes Relat Metab Disord 2004; 28: 1203-1209.

28 Alexy U, Schultze-Pawlitschko V, Sichert-Hellert W, Kersting M. Cluster analysis of individuals with similar trends of fat intake during childhood and adolescence - a new approach to analyzing dietary data. Nutr Res 2005. in press.

29 Cole TJ, Bellizzi MC, Flegal KM, Dietz WH. Establishing a standard definition for child overweight and obesity worldwide: international survey. BMJ 2000; 320: 1240-1243.

30 Alexy U, Sichert-Hellert W, Kersting M, Manz F. The foods most consumed by German children and adolescents: results of the
DONALD Study. Dortmund Nutritional and Anthropometric Longitudinally Design. Ann Nutr Metab 2001; 45: 128-134.

31 Sichert-Hellert W, Kersting M. Fast food consumption in German children and adolescents: results from the DONALD Study. Submitted.

32 Paeratakul S, Ferdinand DP, Champagne CM, Ryan DH, Bray GA. Fast-food consumption among US adults and children: dietary and nutrient intake profile. J Am Diet Assoc 2003; 103: 13321338.

33 Lambe J, Kearney J, Leclercrq C, Berardi D, Zunft HF, Sulzer S, De Henauw S, De Volder M, Lamberg-Allardt CJ, Karkkainen MU, Dunne A, Gibney MJ. Enhancing the capacity of food consumption surveys of short duration to estimate long-term consumeronly intakes by combination with a qualitative food frequency questionnaire. Food Addit Contam 2000; 17: 177-187.

34 Matthys C, De Henauw S, Devos C, De Backer G. Estimated energy intake, macronutrient intake and meal pattern of Flemish adolescents. Eur I Clin Nutr 2003; 57: 366-375.

35 Report of a WHO Expert Committee. Physical status: the use and interpretation of anthropometry. Tech Rep Ser 1995; 854.

36 Schofield WN, Schofield C, James WPT. Basal metabolic rate. Hum Nutr Clin Nutr 1985; 39 (Suppl. 1): 1-96.

37 Gersovitz M, Madden JP, Smiciklas-Wright H. Validity of the 24hr. dietary recall and seven-day record for group comparisons. J Am Diet Assoc 1978; 73: 48-55.

38 Guenther PM, Kott PS, Carriquiry AL. Development of an approach for estimating usual nutrient intake distributions at the population level. J Nutr 1997; 127: 1106-1112.

39 Freudenheim JL, Johnson NE, Wardrop RL. Misclassification of nutrient intake of individuals and groups using one-, two-, three-, and seven-day food records. Am J Epidemiol 1987; 126: 703-713.

40 Lambe J, Kearney J, Leclercq C, Zunft HF, De Henauw S, LambergAllardt CJ, Dunne A, Gibney MJ. The influence of survey duration on estimates of food intakes and its relevance for public health nutrition and food safety issues. Eur J Clin Nutr 2000; 54: 166173.

41 Hoffmann K, Boeing H, Dufour A, Volatier JL, Telman J, Virtanen M, Becker W, De Henauw S, EFCOSUM Group. Estimating the distribution of usual dietary intake by short-term measurements. Eur J Clin Nutr 2002; 56 (Suppl. 2): S53-S62.

42 Hartman AM, Brown CC, Palmgren J, Pietinen P, Verkasalo M, Myer D, Virtamo J. Variability in nutrient and food intakes among older middle-aged men. Implications for design of epidemiologic and validation studies using food recording. Am J Epidemiol 1990; 132: 999-1012.

43 Tarasuk V, Beaton GH. Statistical estimation of dietary parameters: implications of patterns in within-subject variationa case study of sampling strategies. Am J Clin Nutr 1992; 55: 22-27.

44 González-Gross M, Castillo MJ, Moreno LA, Nova E, GonzálezLamuño D, Pérez-Llamas F, Gutiérrez A, Garaulet M, Joyanes M, Leiva A, Marcos A. Alimentación y valoración del estado nutricional de los adolescentes españoles (Estudio AVENA). Evaluación de riesgos y propuesta de intervención. I. Descripción metodológica del proyecto. Nutr Hosp 2003; 18: 15-28.

45 Siega-Riz AM, Popkin BM, Carson T. Differences in food patterns at breakfast by sociodemographic characteristics among a nationally representative sample of adults in the United States. Prev Med 2000; 30: 415-424.

46 Aranceta J, Serra-Majem L, Ribas L, Pérez-Rodrigo C. Breakfast consumption in Spanish children and young people. Publ Health Nutr 2001; 4: 1439-1444.

47 Siega-Riz AM, Popkin BM, Carson T. Trends in breakfast consumption for children in the United States from 1965 to 1991. Am J Clin Nutr 1998; 67: 748S-756S.

48 Reddan J, Wahlstrom K, Reicks M. Children's perceived benefits and barriers in relation to eating breakfast in school with or without universal school breakfast. J Nutr Educ Behav 2002; 34: $47-52$. 
49 Cho S, Dietrich M, Brown CJP, Clark CA, Block G. The effect of breakfast type on total daily energy intake and body mass index: results from the Third National Health and Nutrition Examination Survey (NHANES III). I Am Coll Nutr 2003; 22: 296-302.

50 Morgan KJ, Zabik ME, Stampley GL. Breakfast consumption patterns of US children and adolescents. Nutr Res 1986; 6: 635646.

51 Höglund D, Samuelson G, Mark A. Food habits in Swedish adolescents in relation to socioeconomic conditions. Eur J Clin Nutr 1998; 52: 784-789.

52 Sjöberg A, Hallberg L, Höglund D, Hulthén L. Meal pattern, food choice, nutrient intake and lifestyle factors in The Göteborg Adolescence Study. Eur I Clin Nutr 2003; 57: 1569-1578.

53 Ruxton CHS, Kira TR. Breakfast: a review of associations with measures of dietary intake, physiology and biochemistry. Br J Nutr 1997; 78: 464-470.

54 Bellisle F, Monneuse MO, Steptoe A, Wardle J. Weight concerns and eating patterns: a survey of university students in Europe. Int J Obes Relat Metab Disord 1995; 19: 723-730.

55 Summerbell CD, Moody RC, Shanks J, Stock MJ, Geissler C. Relationship between feeding pattern and body mass index in 220 free-living people in four age groups. Eur J Clin Nutr 1996; 50: 513-519.

56 Gibson SA, O'Sullivan KR. Brekfast cereal consumption patterns and nutrient intakes of British schoolchildren. $J R$ Soc Health 1995; 115: 336-370.

57 Ortega RM, Requejo AM, Lopez-Sobaler AM, Quintas ME, Andres P, Redondo MR, Navia B, Lopez-Bonilla MD, Rivas T. Differences in the breakfast habits of overweight/obese and normal weight schoolchildren. Int J Vitam Nutr Res 1998; 68: 125-132.

58 Bellisle F, Rolland-Cachera MF, Dehheger M, Guilloud-Bataille M. Obesity and food intake in children: evidence for a role of metabolic and/or behavioral daily rhythms. Appetite 1988; 11: $111-118$.

59 Martin A, Normand S, Sothier M, Peyrat J, Louche-Pelissier C, Laville M. Is advice for breakfast consumption justified? Results from a short-term dietary and metabolic experiment in young healthy men. Br J Nutr 2000; 84: 337-344.

60 Drummond S, Crombie N, Kirk T. A critique of the effects of snacking on body weight status. Eur J Clin Nutr 1996; 50: 779 783.

61 Moreno LA, Sarría A, Lázaro A, Bueno M. Dietary fat intake and body mass index in Spanish children. Am J Clin Nutr 2000; 72 (Suppl.): 1399S-1403S.

62 Nicklas TA, Baranowski T, Cullen KW, Berenson GS. Eating patterns, dietary quality and obesity. I Am Coll Nutr 2001; 20: 599-608.

63 Maskarinec G, Novotny R, Tasaki K. Dietary patterns are associated with body mass index in multiethnic women. J Nutr 2000; 130: 3068-3072.

64 Togo P, Osler M, Sorensen TI, Heitmann BL. Food intake patterns and body mass index in observational studies. Int $J$ Obes Relat Metab Disord 2001; 25: 1741-1751.

65 Newby PK, Muller D, Hallfrisch J, Qiao N, Andres R, Tucker KL. Dietary patterns and changes in body mass index and waist circumference in adults. Am J Clin Nutr 2003; 77: 1417-1425.

66 Guo X, Warden BA, Paeratakul S, Bray GA. Healthy eating index and obesity. Eur J Clin Nutr 2004; 58: 1580-1586.

67 Huang TT-K, Howarth NC, Lin B-H, Roberts SB, McCrory MA. Energy intake and meal portions: associations with BMI percentile in US children. . Obes Res 2004; 12: 1875-1885.

68 Alexy U, Sichert-Hellert W, Kersting M. Fifteen-year time trends in energy and macronutrient intake in German children and adolescents: results of the DONALD study. Br J Nutr 2002; 87: 595-604. 